\title{
O fio da meada: relações entre a rede e seus fios ${ }^{1}$
}

\author{
Louise Ronconi de Nazareno ${ }^{2}$
}

\author{
"Você me acha um \\ homem lido, instruído?" \\ "Com certeza" - respondeu Zi-Gong "Não é?" \\ "De jeito nenhum", replicou Confúcio. \\ "Simplesmente consegui achar o fio da meada".
}

Os símbolos são caminhos para entendermos o mundo e organizarmos o caos de nossa experiência dando-lhe ordem. Objetivamos nossas categorias simbólicas e, de algum modo, nós as vemos como produtos da natureza, "coisas", "coisas materiais" que percebemos e reconhecemos. A percepção do mundo através dos símbolos, a criação e as transformações destes, entretanto, não é um problema da sorte. É uma interação contínua entre os caminhos das pessoas para lidar com o universo, físico e social, as relações entre elas e este universo, e o contorno dele mesmo. Esses símbolos têm função comunicadora, além de orientação e organização, e para tanto devem ser compreensíveis não somente para uma pessoa isolada, mas para todo um grupo linguístico.

Os conceitos, como síntese simbólica elaborada, são meios que nos ajudam a colocar a experiência humana em estruturas analíticas coerentes para nossa compreensão. Assim, consideramos que "os conceitos assumem forma na base de experiências comuns, crescem e mudam com o grupo de qual são expressão... desenvolvem-se na fala e na escrita, usados repetidamente até serem instrumentos eficientes de expressão comum... e sobrevivem enquanto experiências cristalizadas tiverem valor existencial no concreto da sociedade" 3 . A partir desta idéias, pretendemos desenvolver o conceito de rede e teia social a partir de obras de Norbert Elias, tentando construir relações ao menos preliminares com outro uso para o termo, o qual indica a formação contemporânea de uma tal conexão mundial de redes comunicativas.

Quando para nós se apresentam palavras, quando elas nos são comunicadas, fazemos uma associação mental com imagens, cheiros, em geral impressões sensitivas que as representam. E também outras impressões, cognitivas, afetivas... Assim, quando nos deparamos com conceitos, procuramos associá-los às impressões conhecidas que temos para compreendêlos, avaliá-los, relacioná-los e organizá-los como nossa memória. Foi esta

\footnotetext{
${ }^{1}$ Este texto foi apresentado como um ensaio final da disciplina Sociologia da Cultura do segundo semestre de 2000.

${ }^{2}$ Graduação - Ciências Sociais/UFPR.

${ }^{3}$ ELIAS, Norbert. O Processo Civilizador Vol I. Rio de Janeiro: Jorge Zahar Ed., 1994, p.26-27.
} 
peculiar e ordinária ação humana de associação que despertou-me o interesse pelo conceito de rede social. No caso, a poderosa associação da palavra à sua imagem diz-nos muito do que se pode esperar do conceito mais elaborado, em um nível de síntese maior. Mas, não devemos esquecer que a associação de um conceito "abstrato" com um objeto, uma coisa concreta, ou a exemplificação de uma relação de síntese elaborada em um objeto material, tem seus limites. O objeto material que já tem seu significado atrelado em primeiro plano à sua função mais concreta, não consegue dar conta de muitas nuances dos conceitos abstratos, de conotações sentimentais e da própria dinâmica de incorporação e reelaboração de significados.

Rede, do latim rete ${ }^{4}$, condensou, em português, vários sentidos em uma só palavra, desde a rede de pesca, até a malha, grade, rede de comunicação, teia, etc... Mentalmente desenhamos aquilo que pode ser uma rede: uma malha, uma tela de fios entrelaçados com aberturas regulares, uma teia, algo que se tece, que faz ligações de nós; pontos em cordas, em arames, em cordéis... Mesmo a rede balançante é tecida em desenho regular, como a rede de pesca... Todas as redes, por sua vez, pressupõem o entrelaçamento, a ligação, a conexão de fios, de unidades menores; com isso "retém-se" alguma coisa: peixes, homens, corrente elétrica, informações. Isso quando falamos da rede enquanto corpo material. ${ }^{5}$

Podemos falar de rede de intrigas, de organizações, rede de fluxos comunicativos, de informações. Pode-se falar da qualidade material da rede como objeto de uso; ou especular a respeito da imagem da rede como qualidade comunicativa de relacionamento entre linguagens, grupo, comuns. Podemos elaborar sua qualidade categórica para o entendimento das relações humanas, ou melhor, discutir sobre a relação da imagem física da rede em relação a seu significado de comunicação que a faz um símbolo interessante para expressar a sociedade. Assim, queremos tratar neste texto, da síntese que expressa a qualidade categórica do conceito de rede para a ciência social. Falamos de um tecido de fios entrelaçados, no qual podemos achar muitos fios da meada. Fios estes que podem ser identificados interpretativamente como os indivíduos nesse tecido de rede, e com os quais jogamos, ambiguamente, para também ser possível interpretá-los como caminhos dentro da imagem de rede.

\footnotetext{
${ }^{4}$ Espanhol: red (de comunicación) - grade, entrelaçamento, armadilha; garlito- rede de pesca; hamaca - maca (de dormir); reseau (de pesca, de cabelo); filet; grillage (de vedação). Inglês: net filó, tule, rede tecido, rede de comunicação...; web - teia, figurativo para rede. Francês: hamac maca, cama.

"Até em expressōes como: "Cair na Rede" ( envolver-se de tal forma que se torna difícil desvencilhar-se) ou "Cabra da Rede rasgada" (Pessoa de vida dissoluta, dissolvida, desfeita, um devasso, um corrupto), apontam para o sentido de envolvimento e vínculo impregnados no conceito, na palavra, na associação que ela provoca.
} 


\section{A rede e seus fios}

Primeiro, precisamos nos desvencilhar da idéia de que indivíduo e sociedade são entidades separadas entre si. Norbert Elias trata muito bem deste assunto em seus livros. Desta discussão, frisaremos apenas alguns pontos em particular. Pois trata-se de uma grande questão sociológica : quem determina quem, sociedade ao indivíduo ou vice-versa? Para nos remetermos a autores clássicos, Durkheim por exemplo, ainda que tome o cuidado de tomar o indivíduo como processo social e verificar nele fontes de ação, acaba por separar sociedade e indivíduo como entidades autônomas, apontando para a preponderância coercitiva e formativa da sociedade sobre o indivíduo. Em Weber, pela sociologia compreensiva, o indivíduo adquire mais importância, embora não se explicite preponderância de um ou de outro; as entidades ainda aparecem separadas: de um lado ações significativas individuais, de outro estruturas burocrátcas, de dominação... Não apontaremos Marx, ou outros, até porque as críticas de Elias recorrem mais aos modelos da Escola Francesa do Pensamento Social.

Ora, pela observação cotidiana, podemos verificar que o indivíduo nasce dependente de outros, cresce dependendo de outros, vive e morre desta maneira. Os nós ${ }^{6}$ entre os indivíduos vão se articulando desde o período prénatal até o fim de sua vida. Não há indivíduo que nasça adulto. A interdependência entre seres individuais é uma condição humana. O homem aprende a ser homem com outros homens.

Não se tem registro de homens, ou de hominídeos, que vivessem sozinhos desde tenra idade. A convivência com os outros molda o caráter humano. Como tratar do homem ${ }^{7}$ como ser isolado e adulto se é através do crescimento, enfim, de seu processo de desenvolvimento em sociedade, que este ser individual ${ }^{8}$ torna-se um homem singular? A estrutura de aprendizagem do indivíduo permite que ele seja cada vez mais singular, mas somente em razão de estabelecer relações e viver com outros indivíduos. As pessoas se ligam pela propensão de sua natureza, ou melhor de sua condição humana.

Sendo menos determinado pela hereditariedade e particularidades de sua espécie, o ser humano sofre uma determinação social muito mais forte e mais interessante, pois é justamente através dela que ele se faz mais singular. No caso da fala, ela não é simplesmente a possibilidade da emissão de sons que

\footnotetext{
${ }^{6}$ Nó: o ponto no qual uma curva (de fio) se entrecorta.

${ }^{7}$ Problema da filosofia iluminista em retirar o homem do seu locus próprio e tratá-lo como entidade universalizante, pronta, autônoma... Embora Elias atribua o caráter universal de humanidade, ele assenta esta característica nas "propriedades" sociais, no princípio, da existência social deste ser humano.

${ }^{8}$ Individua -ser singular da espécie, indivisível, único. ELIAS, Norbert. A Sociedade dos Indivíduos. Rio de Janeiro: Jorge Zahar Editora, 1994.
} 
nos diferencia dos animais, já determinada pelo aparelho fonético, mas o discurso, a comunicação, ou seja, a articulação da palavra ao significado, ao conteúdo e à maneira de falar, que dependem do aprendizado do homem na coletividade. E este é um exemplo clássico de Aristóteles, contemporaneamente retomado por Hannah Arendt e Norbert Elias, entre outros. O próprio corpo, o organismo, a matéria que identificamos como sendo "o homem" é um substrato de um processo de desenvolvimento. A postura, os gestos, o vestuário, o embaraço, as expressões faciais, as medidas corporais são manifestações desse processo.

"Graças à autoregulação humana livre do controle de mecanismos reflexos hereditários, o manejo das relações pelo indivíduo permite-e também exige-um grau de moldagem social muito superior ao de outros animais. Graças a essa moldagem social, a estrutura do comportamento, a forma de autoregulação em relação aos outros, é mais diversificada no homem do que em todos os outros animais; e graças a ela, essa autoregulação torna-se, em suma, mais "individual" 9

O homem nasce dentro de uma estrutura já organizada, nasce de outros dois seres, e precisará de muitos outros seres para aprender, para se formar, conformar, moldar e desenvolver. Nascendo num grupo já existente o indivíduo, ou os indivíduos, formam um continuum sócio-histórico do qual cada pessoa participa crescendo, e é partilhada pelos outros como também os partilha. Como desenvolve Elias, a história vai sendo construída pelas pressões exercidas por essas pessoas vivas a outras pessoas vivas, dando singularidade a épocas e configurações sociais. Não há deliberação individual de tal ou qual rumo para a história. Do que podemos concluir que, a margem individual de decisão está sempre limitada às tramas sociais; depende dos instrumentos de poder controlados por grupos, das configurações do poder e do potencial de inserção ou transgressão perante essa configuração formada pelos indivíduos. De certa forma o indivíduo não escapa do espaço conferido por seu nascimento. Desde aí, abre-se o seu leque de opções possíveis para ação, entretanto, a performance de ação, esta sim, pertence, somente, ao próprio ser.

"O que cabe ser frisado aqui é o simples fato de que mesmo na sociedade civilizada, nenhum ser humano chega civilizado ao mundo e que o processo civilizador individual que ele obrigatoriamente sofre é uma função do processo civilizador social (...) desde que, em nossa sociedade, todo ser humano está exposto desde o primeiro momento de vida à influência e à intervenção modeladora de adultos civilizados ele deve de fato passar por um processo para atingir o padrão alcançado por sua sociedade no curso da história, mas não através das fases históricas individuais..."

\footnotetext{
${ }^{9}$ ELIAS, Norbert. A Sociedade dos Indivíduos. Rio de Janeiro: Jorge Zahar Ed., 1994, p. 38

${ }^{10}$ ELIAS, Norbert. O Processo Civilizador Vol. I . Rio de Janeiro: Jorge Zahar Editora, 1994, p.15.
} 
Portanto, o desenvolvimento do conceito de indivíduo, que atualmente produz a imagem de isolamento entre ser e sociedade, faz-se em conjunto com as mudanças nos padrões da sociedade e na maneira como o homem pensa as coisas e si próprio. Advindo do emprego pelos escolásticos, de individua, representando a singularidade do caso isolado de uma espécie, o termo indivíduo atualmente remete a muito mais do que singularidade. Provavelmente, como descreve Elias, os personagens humanistas que ocuparam cargos nacionais identificados por progressos pessoais contribuiram para uma afirmação de individualidade. A atribuição de genialidade a certas personagens na história, compositores, chefes de Estado, pensadores, faz estas imagens serem aceitas pela modernidade, como constructos individuais e muitas vezes inquestionáveis. ${ }^{11}$

\section{O processo de tecelagem}

Essa sensação, essa idéia, essa imagem de isolamento e de autonomia individual tem raízes e se faz em um processo, chamado por Elias civilizador. Ele pode ser tomado como uma grande onda planetária, mas que funda-se a partir da sociedade Ocidental, e que na sociologia de Elias é um modelo de entendimento da história Ocidental e da humanidade, sem desconsiderar outras culturas, mas simplesmente porque o modo, o processo, a onda Ocidental quer abranger, e abrange todo o planeta física e ideologicamente.

$\mathrm{O}$ desenrolar histórico de mudanças ${ }^{12}$ no sentido de um processo civilizador produziu no homem a ilusão de seu isolamento perante os outros homens e a sociedade. As funções e papéis sociais foram se diferenciando e crescendo, reorganizando os relacionamentos humanos. As relações de interdependência se complexificaram, tornando cada ser mais dependente de outro. Entretanto, com suas funções tão específicas e diferenciadas, o isolamento perante o total promove o sentimento de separação e independência. Como descreve Marx, a alienação do homem, da produção, de seu trabalho e enfim de si mesmo. Uma alienação que diz respeito às tarefas e papéis que os homens desempenham em sociedade vinculada aos sentimentos de pertencimento e comportamentos advindos desse pertencimento.

"Do período mais remoto da história do Ocidente até nossos dias, as funçōes sociais, sob pressão da competição, tornaram-se cada vez mais diferenciadas. Quanto mais diferenciadas elas se tornavam, mais crescia o número de funções, e assim, de pessoas

\footnotetext{
"Sobre o assunto, ver o trabalho de Elias: Mozart, sociologia de um Gênio. Rio de Janeiro: Jorge Zahar Editora, 1995.

12 "a mudança é uma característica normal da sociedade. Uma sequência estrutural de mudança contímua serve aqui como marco de referência para a investigação de estados localizados, em pontos particulares no tempo." lbdem, p.222.
} 
das quais o individuo constantemente dependia em todas suas ações, desde as mais simples e comuns até as complexas e raras. À medida que mais pessoas sintonizavam sua conduta com a de outras, a teia de açöes teria que se organizar de forma sempre mais rigorosa e precisa, a fim de que cada ação individual desempenhasse uma função social" ${ }^{13}$

Assim, a noção de individualidade, não apenas como singularidade, mas como autonomia e independência, está fundamentada nas remodelações das configurações sociais ocidentais, no rumo do processo civilizador. Pois que esse processo não somente atua como controle de comportamentos manifestos, mas também como autocontrole singular em cada ser, agindo em sua estrutura psíquica $^{14}$. Com o avanço das estruturas de autocontrole, conscientes ou inconscientes, o homem faz da sua dependência cada vez mais algo individual. É um paradoxo: quanto mais autônomo é o ser humano moderno, mais dependente da sociedade ele se torna. Queremos reforçar que a interdependência dos indivíduos na cadeia social está se fazendo através de sua individualidade. Pois, por menor que seja o grau de consciência dessa interdependência, o indivíduo desempenha seu papel cada vez mais conectado com a rede social, e esse papel está cada vez mais interiorizado pelo indivíduo. Não só pelo controle externo que nos faz lembrar dos direitos e deveres (na verdade, muito mais e apenas, dos deveres), mas pela identificação que fazemos dos nossos papéis.

\begin{abstract}
"a teia de ações tornou-se tão complexa e extensa, o eșforço de comportar-se corretamente dentro dela ficou tão grande que, além do autocontrole consciente do individuo, um cego aparelho automático de autocontrole foi firmemente estabelecido... a direção dessa transformação da conduta, sob a forma de uma regulação crescentemente diferenciada de impulsos, era determinada pela direção do processo de diferenciação social, pela progressiva divisão de funções e pelo crescimento de cadeias de interdependência nas quais, direta ou indiretamente, cada impulso, cada af̧ão do individuo tornavam-se integrados"15
\end{abstract}

Os papéis e as funções sociais são reservados e construídos na teia social, e os indivíduos aprendem e ajustam-se gradativamente a esses papéis de acordo com sua inserção social, seu desenvolvimento, seus gostos pessoais, sua educação. Através do processo civilizador individual, aquele pelo qual qualquer criança passa, ao enfrentar o aprendizado na família, nas escolas, nas ruas, até a

\footnotetext{
${ }^{13} \mathrm{Ibdem}$, Vol II p. 196.

14 “...destaca, mais uma vez, as ligações entre mudanças na estrutura da sociedade e mudanças na estrutura do comportamento e da constituição psíquica." ELIAS, Norbet. O Processo Civilizador, Vol I. Rio de Janeiro: Jorge Zahar Editora, 1994, p. 17. Lembrando sempre que não podemos dizer que Elias trabalha com modelos de dependência, ou seja, que ele subordine estrutura psíquica à estrutura social ou vice-versa.
}

${ }^{15}$ ELIAS, Norbert. O Processo Civilizador, Vol II. Rio de Janeiro: Jorge Zahar editora, 1994, p.196. 
idade adulta, o homem apreende o processo social, adapta-se às estruturas e conjunturas. Se temos, todavia, um sentido geral de civilização, é certo afirmarmos que formas diferenciadas de colocação e de geração de indivíduos civilizados convivem ao mesmo tempo. Essas formas se constituem em habitus de grupos, no sentido desenvolvido por Pierre Bourdieu. Funcionando também, como diz Elias, como auto-imagem e composição social, um conhecimento adquirido de si mesmo e capacidade geradora/criadora.

\begin{abstract}
"(habitus) sistema de disposições duráveis, estruturas estruturadas predispostas a funcionar como estruturas estruturantes, isto é, como princípio que gera e estrutura as práticas e as representaçöes que podem ser objetivamente regulamentadas e reguladas sem que por isso sejam o produto de obediência de regras, objetivamente adaptadas a um fim, sem que se tenha a necessidade de projeção consciente deste fim ou domínio das operações para atingi-lo, mas sendo, ao mesmo tempo, coletivamente orquestradas sem serem produtos da ação organizada de um maestro... "16
\end{abstract}

A noção de habitus, cabe aqui ressaltar, serve para reafirmarmos a natureza processual e social do indivíduo. Será através de uma disposição incorporada - do habitus - que o indivíduo se reconhecerá, será reconhecido incorporado na sociedade. Para determinado habitus elege-se uma determinada quantidade de funções pertinentes e coerentes para tal. Como identificamos o habitus como algo não descolado do indivíduo, não caberia dizer que trata-se de uma camisa de força, pois que é o indivíduo que gera e é gerado nele, correspondendo ao processo civilizador individual .

Neste sentido, não cabe falarmos de uma determinação da sociedade sobre o indivíduo, ou vice-versa, já que não podemos tratá-los independentemente um do outro. O conceito de sociedade só faz sentido se incluirmos os indivíduos, e o conceito de indivíduo só adquire sentido se tratado a partir de sociedade. Assim como esta não surge de um contrato deliberado de indivíduos, também não se caracteriza por uma entidade supraindividual planejada, que tem propósitos e fim certos, aos quais se submetem as pessoas..."De planos emergindo, mas não planejada, movida por propósitos, mas sem finalidade" ${ }^{17}$. É por isso que a imagem de rede faz tanto sentido nos textos de Elias.

O conceito de rede em Elias cumpre um papel importante no sentido de que representa uma imagem morfológica das relações sociais, expressando assim a coerência entre sociedade e indivíduo, reforçando a crítica à dicotomia determinista entre os dois termos. Não se trata apenas de uma imagem recorrente para falar de algumas relações sociais. Todavia, é um símbolo forte, pertinente às suas afirmações. Os fios não compõe a rede independentemente

\footnotetext{
${ }^{16}$ BOURDIEU, Pierre. Economia das Trocas Simbólicas. Sào Paulo: editora Perspectiva, 1999.

${ }^{17}$ ELIAS, Norbert. A Sociedade dos Indivíduos. Rio de Janeiro: Jorge Zahar editora, 1994, p..59
} 
uns dos outros, tecem e são tecidos, em conjunto. E só a partir de seu conjunto se faz a imagem de rede, no sentido das relações que fazem, só porque se entrelaçam, só porque formam um desenho em conjunto, que pode ser chamado rede.

“...cada pessoa singular está presa por viver em permanente dependência funcional de outras, ela é um elo nas cadeias que ligam outras pessoas... Essas cadeias não são visíveis e tangíveis, como grilhões de ferro. São mais elásticas, mais variáveis, mais mutáveis, porém não menos reais, e decerto não menos fortes. E é essa rede de funções que as pessoas desempenham umas em relação a outras, a ela e nada mais, que chamamos 'sociedade". 18

Embora a Constelação seja a imagem preferida para se falar de sociedade e indivíduo em Elias, não podemos afirmar que o fim das estrelas seja formar as constelações, já que estas próprias são enxergadas e delimitadas por nós mesmos, nem tampouco podemos dizer que as constelações têm o fim de mostrar tal ou qual estrela, ou juntá-las simplesmente. Mesmo assim, quando se trata das relações entre indivíduos, funções e estrutura social, não podemos fugir do que seria a rede, a teia social.

"A ordem invisível dessa forma de vida em comum, que não pode ser diretamente percebida, oferece ao individuo uma gama mais ou menos restrita de funções e modos de comportamento possiveis. Por nascimento, ele está inserido num complexo funcional de estrutura bem definida, deve conformar-se a ele, moldar-se de acordo com ele e, talvez, desenvolver-se mais, com base nele. Até sua liberdade de escolha entre funções preexistentes é bastante limitada. Depende largamente do ponto em que ele nasce e cresce nessa teia humana, das funções e da situação de seus pais..."

\section{A rede e os fluxos (outra imagem/idéia)}

Contemporaneamente, a imagem da rede está marcada pela internet (no significado literal rede internacional). Falamos de uma outra apropriação da imagem de rede, não somente do modelo morfológico de Elias, mas também da saliência da importância dos nós desta rede como modelo social. O uso está dado, principalmente, pelas mudanças tecnológicas nos sistemas de comunicação e informação. O significado apropriado para dar novo sentido a essa configuração social é a de troca de fluxos, circuito, advindo da noção de rede de transmissões, conexão de pontos. Os nós dão a possibilidade dos fluxos de dependência, não somente entre indivíduos, mas entre coorporações, instituições... Eles saltam como imagem preponderante. Fundamentalmente

\footnotetext{
${ }^{18}$ Ibdem, p. 23

${ }^{19}$ Ibdem, p. 21. 
ligado aos processos da informática que difundiram a informação através de linhas virtuais de acesso globalizado.

"Redes constituem a nova morfologia social de nossas sociedades e a difusão da lógica
de redes modifica de forma substancial a operafão e os resultados dos processos
produtivos e de experiência, poder e cultura."

Uma sociedade em redes pressupõe o conectar e desconectar dos assuntos pertinentes à realização de objetivos, no modo de fluxos. Não é tanto a interdependência entre pessoas e organizações, mas dos fluxos que se fazem entre as interdependências. É o paradigma da tecnologia da informação que se expande, penetrante em toda estrutura social. As redes comunicativas são estruturas abertas, em que podem ser tecidos infinitos nós, desde que tenham códigos comuns e predisposições comuns para a integração nesta rede. Em fato, "o poder dos fluxos é mais importante que os fluxos do poder." $\mathrm{E}$ se isso se confirma trata-se de mais um reforço para afastar os indivíduos das fontes de decisões, assentar o sentimento de impotência frente às questões do mundo, fazendo frente as suas pequenas decisões diárias. Neste modelo de rede os indivíduos não têm claros os seus papéis, pois que muito mais visíveis tornamse os papéis dos nós de fluxos comunicativos.

Há uma reestruturação das relações humanas tendo em vista as modificações na tecnologia dos sistemas comunicativos, que oferece a possibilidade de uma comunicação global. A transformação dos lugares de decisões, de poder, para o espaço virtual e um tempo intemporal ${ }^{22}$, para usar a terminologia de Manuel Castells, numa reordenação em rede: as conexões que ligam as redes representam os instrumentos privilegiados do poder. Uma exigência da adaptabilidade e flexibilização dos trabalhos, posto como valor não o trabalho, mas a característica da flexibilidade $\mathrm{e}$ da adaptabilidade do mesmo. Também, prega-se a desvinculação da cultura vis a vis as bases materiais da existência, impondo-se uma cultura de desconstrução e construção contínuas, de briccolage. Inúmeras mudanças globais, mundiais nos relacionamentos humanos, tendo como fundamento o valor das configurações em fluxo, em contrapartida à integração de outros tantos seres humanos como humanidade, que porém não nos cabe aprofundar aqui, mesmo em se tratando de um tema certamente inquietante (pois que não temos intenção de demonizar a tecnologia).

${ }^{20}$ CASTELLS, Manuel. A Sociedade em Rede (A era da informação: economia, sociedade e cultura; v.1). São Paulo: Editora Paz e Terra, 1999, p. 497.

${ }^{21}$ Ibdem, p. 497.

${ }^{22} \mathrm{O}$ tempo que não está marcado e cronometrado a partir de eventos físicos, e que portanto podem coincidir, em todos os lugares, além de alienarem-se dos próprios objetos que marcavam as sucessōes de eventos (relógios).

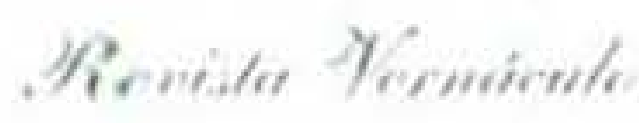


Há também a fatalidade do domínio do capital, pensado como idéia dos centros do poder, mas que não pode ser tomado como determinação para todos os micro-poderes que perpassam as relações sociais. Não podemos esquecer da sofisticação existente em todas as formas de trocas humanas.

\begin{abstract}
"Sociedade capitalista, e o modo de produção capitalista dá forma às relações sociais em todo planeta... o capital é global e está estruturado em rede de fluxos financeiros (é também virtual)... Há uma entidade capitalista coletiva sem rosto, formada de fluxos financeiros operados por redes eletrônicas..." ${ }^{23}$
\end{abstract}

A lógica de rede modifica e impõe modificações às sociedades. Todavia, o paradigma tecnológico não é universal, é parcial contemporaneamente; se a tecnologia assume papel organizador fundante de certa imagem de rede, e distribuição de poder, informação, comando, interatividade, não constitui-se como modelo único, embora seja imposto pelos seus centros de propagação e poder como inexorável. Mas, escolhendo o discurso do inexorável... quando, por um lado, vivemos uma cultura hightechs, um povo mundializado via internet e ciberespaço... vivemos também num mundo onde existe "um outro povo" condicionado aos limites das bases materiais de sobrevivência. Um povo, porque não queremos nos referir a classes, que está excluído do ciberespaço e de todas as instâncias decisórias de poder, e para quem, muitas vezes, o "outro povo, aquele incluído," parece de outro mundo.

A ilusão de isolamento parece crescer ainda mais neste rumo civilizatório, porque afasta não o indivíduo de outro indivíduo, mas um tipo de indivíduo de outro tipo, cindindo a humanidade. Justamente por isso, não nos referimos anteriormente a classes, mas a povo. Essa cisão é coerente com esse processo, pois que, se pelos avanços tecnológicos possibilita-se de um lado a integração de um "tipo de humanidade", também, por outro, reserva somente para "essa humanidade" as decisões que envolvem, por conseguinte, apenas os assuntos, problemas, dilemas, que interessam e que fazem parte "dessa humanidade", excluindo a outra humanidade.

Cria-se um habitus social de um grupo vinculado às idéias de um mundo globalizado, vivendo de fluxos virtuais, conexões cibernéticas, capitais financeiros, trabalhos flexíveis, usufruto das tecnologias. Um habitus da cultura pós-moderna para os que têm dinheiro, instrução e conhecimento sobre os códigos informacionais dessa cultura, na ilusão de que esse habitus é a realidade que acontece no mundo. Enquanto aqueles despossuídos de capital e dos meios de produção, sem informação e conhecimento, sem conexão tecnológica, sem virtualismo, sem ciberespaço, constróem o dia-dia da venda

\footnotetext{
${ }^{23}$ Ibdem, p.500/502.
} 
da força de trabalho, má remuneração, das doenças que pareciam ter-se erradicado, da falta de comida, etc. E sobre esse povo sem a propriedade dos meios produtivos e interativos, e em cima deste, o ciberespaço se realiza. A cisão opera no conflito de classes, no conflito de Estados, no conflito de povos, no conflito da idéia sobre humanidade..

Será que é possível perceber um sentimento de identificação entre os indivíduos do mundo todo, que ultrapasse a dimensão do ciberespaço, um sentimento que dê sentido às discussões dos Direitos Humanos, dos Movimentos Ecologistas? Ou seja, uma corrente que possibilite uma integração humana no maior nível de síntese? Deste ponto só nos resta especular como faz Elias: "a abolição de guerras entre os subgrupos humanos e a geração de um sentimento de nós em toda a humanidade seriam indubitavelmente mais fáceis se ela fosse ameaçada de aniquilação por uma espécie alienígena,24. Talvez, não podemos averiguar uma corrente contra a fatalidade imposta de uma humanidade cindida (muito mais profundamente do que no início da Revolução Industrial), talvez sejam várias, seja a sofisticação de trabalhar as trocas e modificar a fatalidade. Todavia, esse já pode ser um outro tema de ensaio.

\section{Bibliografia}

BOURDIEU, Pierre. Economia das Trocas simbólicas. São Paulo: editora Perspectiva, 1999.

CASTELLS, Manuel. A Sociedade em Rede (A era da informação: economia, sociedade e cultura; v.1). São Paulo: Editora Paz e Terra, 1999.

ELIAS, Norbert. A Sociedade dos Indivíduos. Rio de Janeiro: Jorge Zahar Ed., 1994.

O Processo Civilizador. Vol I. Rio de Janeiro: Jorge Zahar Ed.,

1994.

Sobre o Tempo. Rio de Janeiro: Jorge Zahar Ed., 1998.

${ }^{24}$ ELIAS, Norbert. A Sociedade dos Indivíduos. Rio de Janeiro: Jorge Zahar Editora, 1994, p. 187. 